\title{
Chapter 19 \\ Imaging Techniques for Radiocesium in Soil and Plants
}

\author{
Ryohei Sugita, Atsushi Hirose, Natsuko I. Kobayashi, Keitaro Tanoi, \\ and Tomoko M. Nakanishi
}

\begin{abstract}
Various radioisotope imaging techniques have been used at the Graduate School of Agricultural and Life Sciences, University of Tokyo, to analyze samples containing radiocesium $\left({ }^{137} \mathrm{Cs}\right.$ and $\left.{ }^{134} \mathrm{Cs}\right)$. There are two types of samples: (1) environmental samples contaminated by the fallout from the Fukushima Daiichi nuclear power plant accident, which contain relatively low concentrations of radiocesium and (2) laboratory samples from tracer experiments conducted at the radioisotope institution containing relatively high concentrations of ${ }^{137} \mathrm{Cs}$. The first technique used to visualize radiocesium in soil and plants was radioluminography (RLG). RLG, which makes use of an imaging plate, has a dynamic range that is large enough to detect both environmental and tracer-added samples. To quantify radiocesium distributions, the samples were frozen and sliced before contact with the imaging plate. This freezing procedure after sampling is for preventing radiocesium movement during slicing and measurement of ${ }^{137} \mathrm{Cs}$ distribution. After slicing, two detection methods were employed: RLG and microautoradiography (MAR). MAR is the conventional and older method for imaging radioisotopes based on the daguerreotype process. We applied this method to frozen sections and obtained ${ }^{137} \mathrm{Cs}$ distributions at a higher resolution than with RLG. Following this, we employed a non-destructive method for imaging ${ }^{137} \mathrm{Cs}$ movement in a living plant. We developed the visualization technique called real-time radioisotope imaging system and then demonstrated ${ }^{137} \mathrm{Cs}$ movement from soil to rice plants using a chamber containing paddy soil, water, and rice plants. Lastly, ${ }^{42} \mathrm{~K}$ obtained by ${ }^{42} \mathrm{Ar}-{ }^{42} \mathrm{~K}$ generation enabled a comparison between the movement of ${ }^{137} \mathrm{Cs}$ and ${ }^{42} \mathrm{~K}$. The mechanism of $\mathrm{Cs}$ transport has been reported to have some relationship with the $\mathrm{K}$ transport system, so experiments using both ${ }^{137} \mathrm{Cs}$ and ${ }^{42} \mathrm{~K}$ would be useful for clarifying the mechanism in more detail.
\end{abstract}

Keywords Fukushima Daiichi nuclear power plant accident $\bullet$ Imaging plate $\bullet$ Live imaging - Microautoradiography - Radiocesium • Radioisotope imaging • Radioluminography • Real-time radioisotope imaging • Soil • Whole-plant imaging $\bullet{ }^{137} \mathrm{Cs}$ distribution

R. Sugita • A. Hirose • N.I. Kobayashi • K. Tanoi $(\varangle) \bullet$ T.M. Nakanishi

Graduate School of Agricultural and Life Sciences, The University of Tokyo, 1-1-1 Yayoi,

Bunkyo-ku, Tokyo 113-8657, Japan

e-mail: uktanoi@mail.ecc.u-tokyo.ac.jp 


\subsection{Radioluminography}

\subsubsection{Radioluminography Using an Imaging Plate}

Radioluminography (RLG) is a type of autoradiography (ARG) based on stimulated luminescence and is widely used to visualize radiation from samples. Before the RLG technique was established, ARG using X-ray film was employed for visualization, despite its difficulties in handling, low quantitativity, and low sensitivity. We used the imaging plate (IP) (Fuji Film) as a stimulable phosphor plate because it has the advantage of a wide dynamic range of determination, re-usability, and high sensitivity.

There are many techniques available for detecting ${ }^{137} \mathrm{Cs}$ in samples and for measuring gamma ray emissions. For example, the germanium semiconductor detector and sodium iodide scintillation counter are often used for general determinations. These techniques are more suitable for ${ }^{137} \mathrm{Cs}$ determination compared to ARG because ARG mainly detects the beta rays of ${ }^{137} \mathrm{Cs}$, which are easily selfabsorbed in thick samples Nevertheless, ARG using an IP (i.e., RLG) has been a useful technique for observing ${ }^{137} \mathrm{Cs}$ distribution in thin samples from fields in Fukushima or in samples from the radioisotope laboratory. RLG has been used to quantify ${ }^{137} \mathrm{Cs}$ and other nuclides in plant samples (Kanno et al. 2007; Sugita et al. 2014).

A sample is placed in contact with the IP for a period of time that is dependent on the radiation level in the sample. During sample exposure to the IP, radiation photostimulates the fluorescent material attached to the IP and a radiation image is recorded. The radiation image is then analyzed by a He-Ne laser-based imaging system. The photostimulated fluorescent material releases its fluorescence as it is scanned by the laser, and the fluorescence is sequentially detected and digitized by the imaging system. The intensity of the fluorescence is called the photostimulated luminescence value, which has a linear relationship with radiation intensity up to at least five orders of magnitude. Conveniently, the afterimage on the IP can be eliminated by white fluorescence; hence, the IP can be used repeatedly. The sensitivity of the IP was more than 10 times higher than X-ray film, even though the exposure time for the environmental samples was longer on the latter due to their low radiocesium activity. To detect low radiocesium activity, we performed the exposure inside a shield made of lead and copper at around $4{ }^{\circ} \mathrm{C}$ (Fig. 19.1). The shield is expected to prevent exposure to background radiation and the low temperature can reduce fading during the long exposure time (Suzuki et al. 1997).

Because the RLG technique is easy to handle and generic in life science research, many samples derived from the Fukushima Daiichi nuclear power plant accident have been examined, which include the following: leaves of Japanese Beech (Fagus crenata) and needles of Japanese Black Pine (Pinus thunbergii) (Koizumi et al. 2013); soil, bamboo, and mushroom (Niimura et al. 2014); branches and leaves of Cryptomeria japonica, branches and leaves of Thujopsis dolabrata var. hondae, branches and leaves of Prunus percica, branches and roots of Morus 

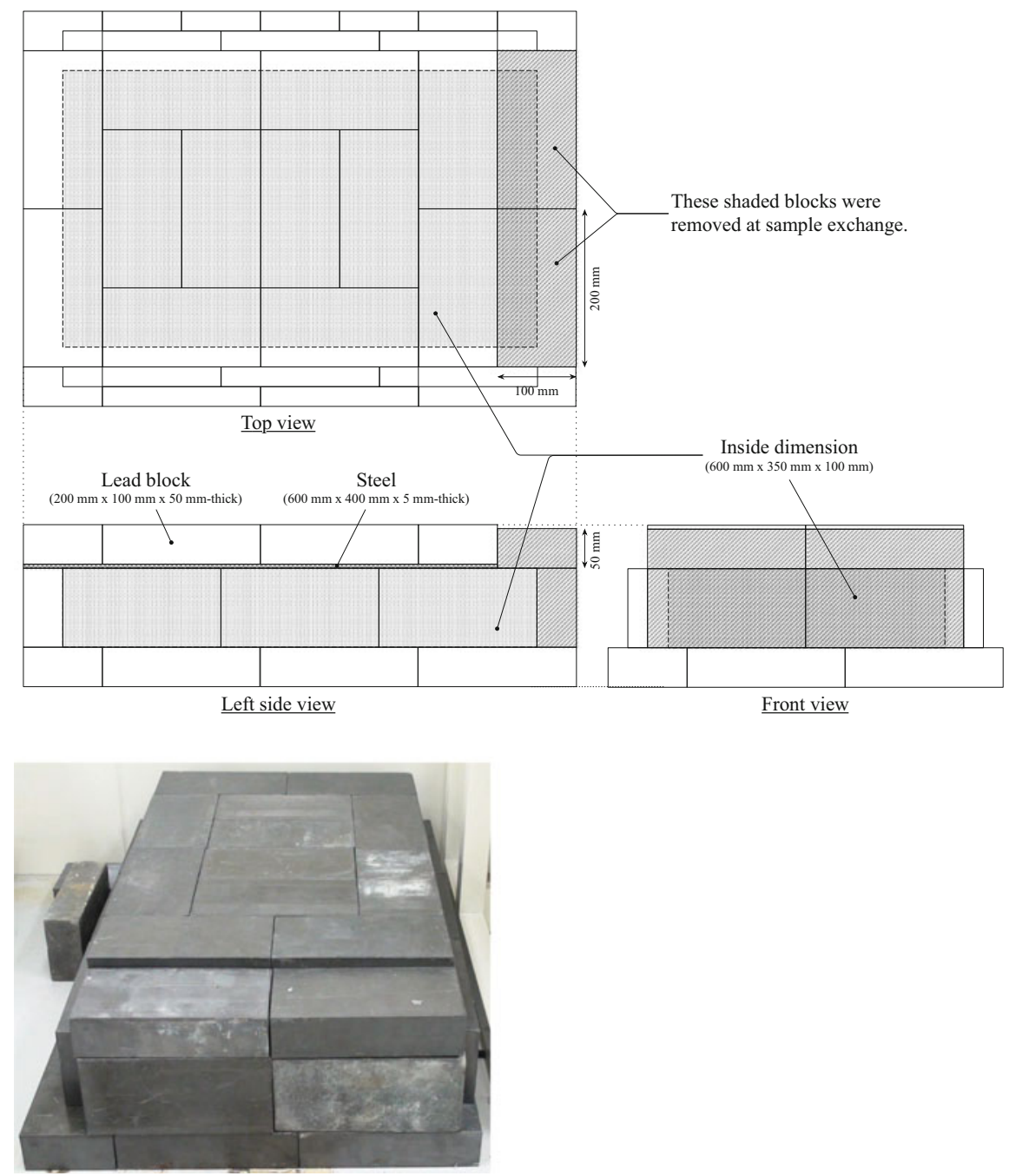

Fig. 19.1 The lead shield employed for detecting the low level of radiation

alba, lichen Permotrema tinctorum, and internodes and shoots of Phyllostachys bambusoides (Sakamoto et al. 2013); skeletal muscle of pig (Yamaguchi et al. 2013); green onion, carrot, and lettuce (Isobe et al. 2013); leaves of C. japonica, fallen leaves of Quercus serrata, and fallen leaves of Pedicularis densiflora (Tanaka et al. 2013); soil particles (Mukai et al. 2014); leaves of Sasa palmate, Taxus cuspidate, Quercus serrate, Trifolium spp., and Equisetum arvense (Mimura et al. 2014); leaves of cabbage and spinach (Shiba et al. 2013); leaves of bamboo and oak, and trunks of cedar tree and pine tree (Nakajima et al. 2014); leaves of beech, pieris, and oak (Furuta 2013); soil, plant, and dust samples (Itoh 


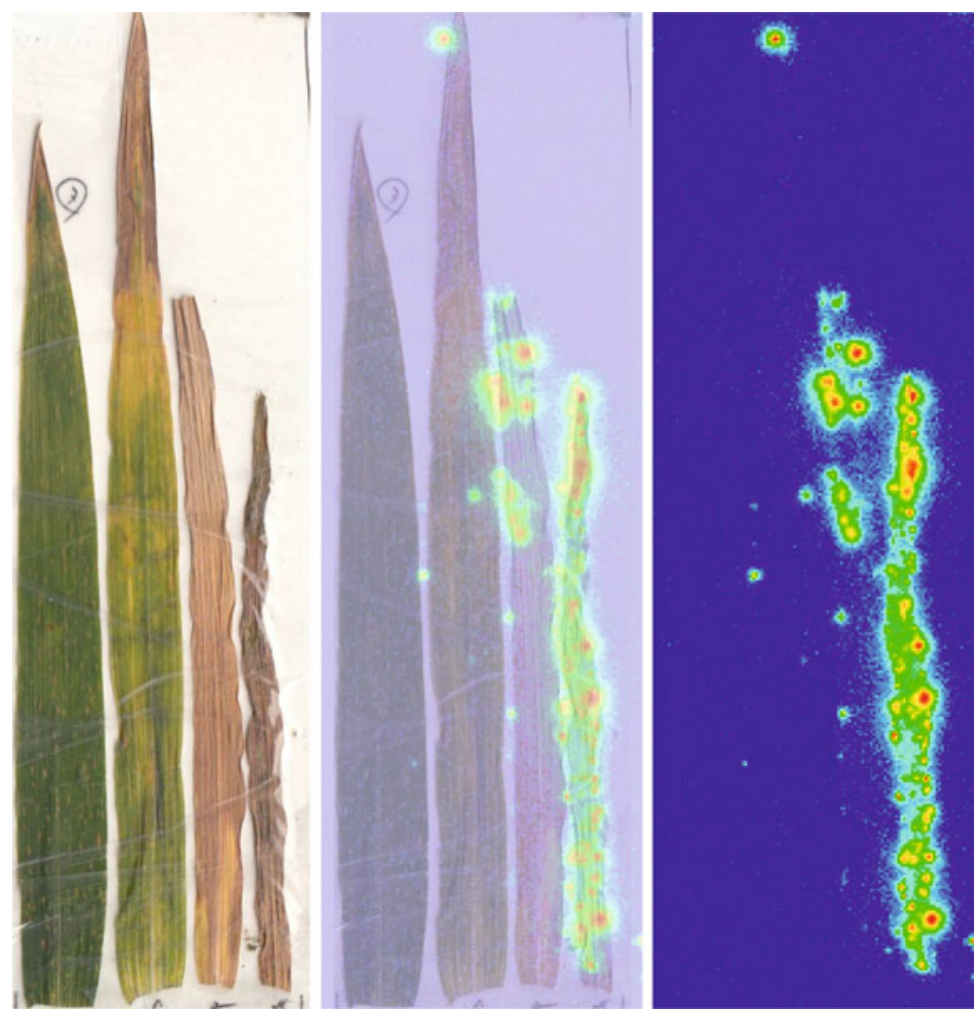

Fig. 19.2 The example of radiocesium image of barley leaves in May 2011 by radioluminography (RLG)

et al. 2014); filters (Zeissler et al. 2013); leaves and ears of wheat and barley (Tanoi et al. 2011; Tanoi 2013); soil, leaves of wheat, branches, leaves and fruits of peach, and rice plants (Nakanishi et al. 2012); bark of Rhus vernicifera DC. (Mori et al. 2012); bamboo (Phyllostachys reticulate (Rupr.) K. Koch) (Nakanishi et al. 2014); and branches of peach (Takata et al. 2012).

Most of the radioluminograms pointed out that direct contamination was observed as dots on leaves as well as on soils (Fig. 19.2), these dots having been observed as long as several years after the Fukushima Daiichi nuclear power plant accident. On the other hand, some images, such as rice plants (Nakanishi et al. 2012) and bamboo shoots (Nakanishi et al. 2014), showed a radiocesium distribution indicating possible (cesium) transportation inside/within the plant. 


\subsubsection{Radioluminography with Frozen Sections}

The RLG images mentioned in the previous paragraph indicate how the contaminated nuclides were distributed in a sample at a centimeter or subcentimeter resolution (Fig. 19.3). To visualize the contamination in more details, it is necessary
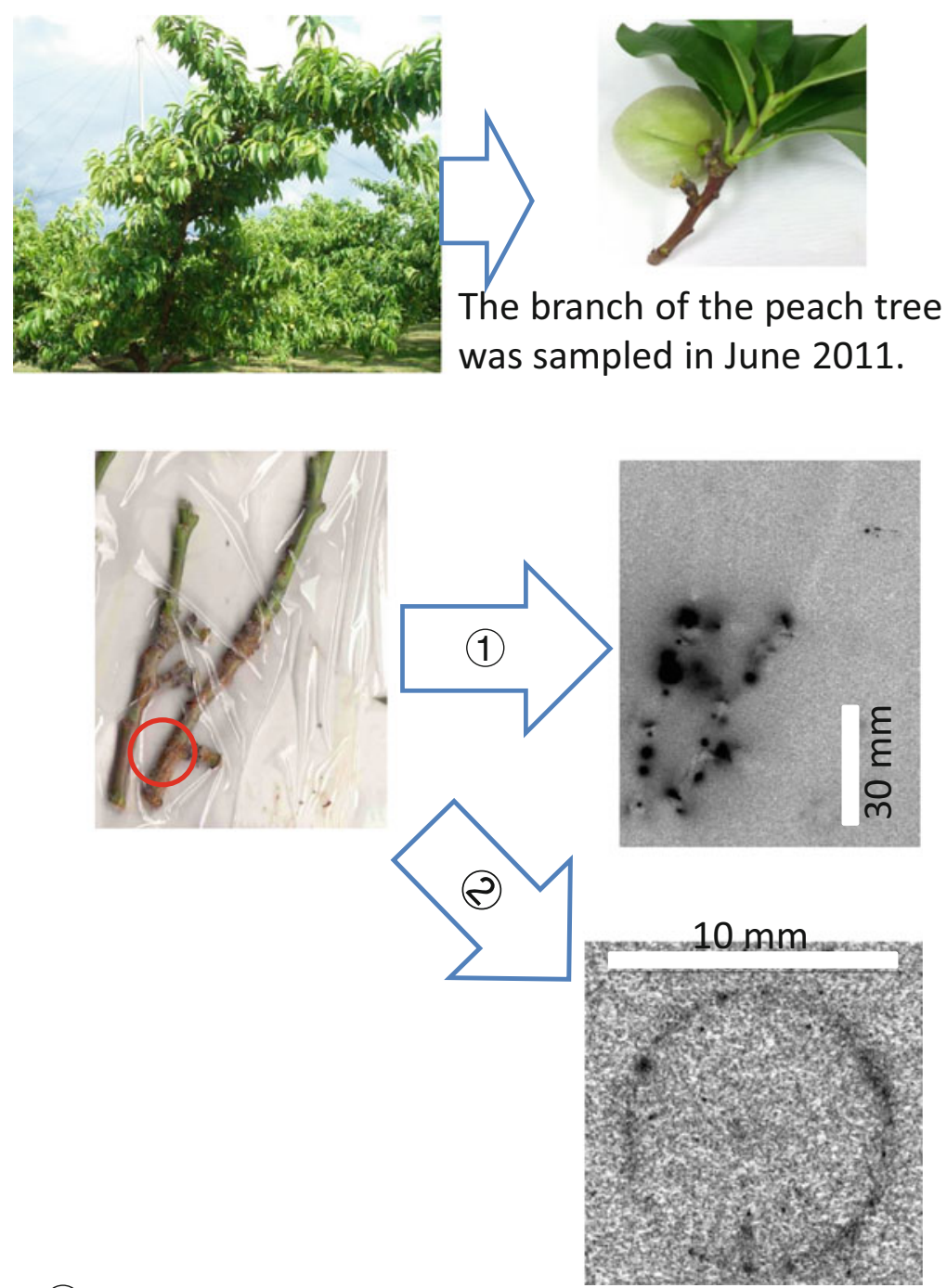

(1)The branch was exposed to an IP directly.

(2) The branch was kept under frozen condition. And the cross section of the branch was exposed to an IP.

Fig. 19.3 The different procedures between general RLG (1) and RLG with frozen sections (2) 

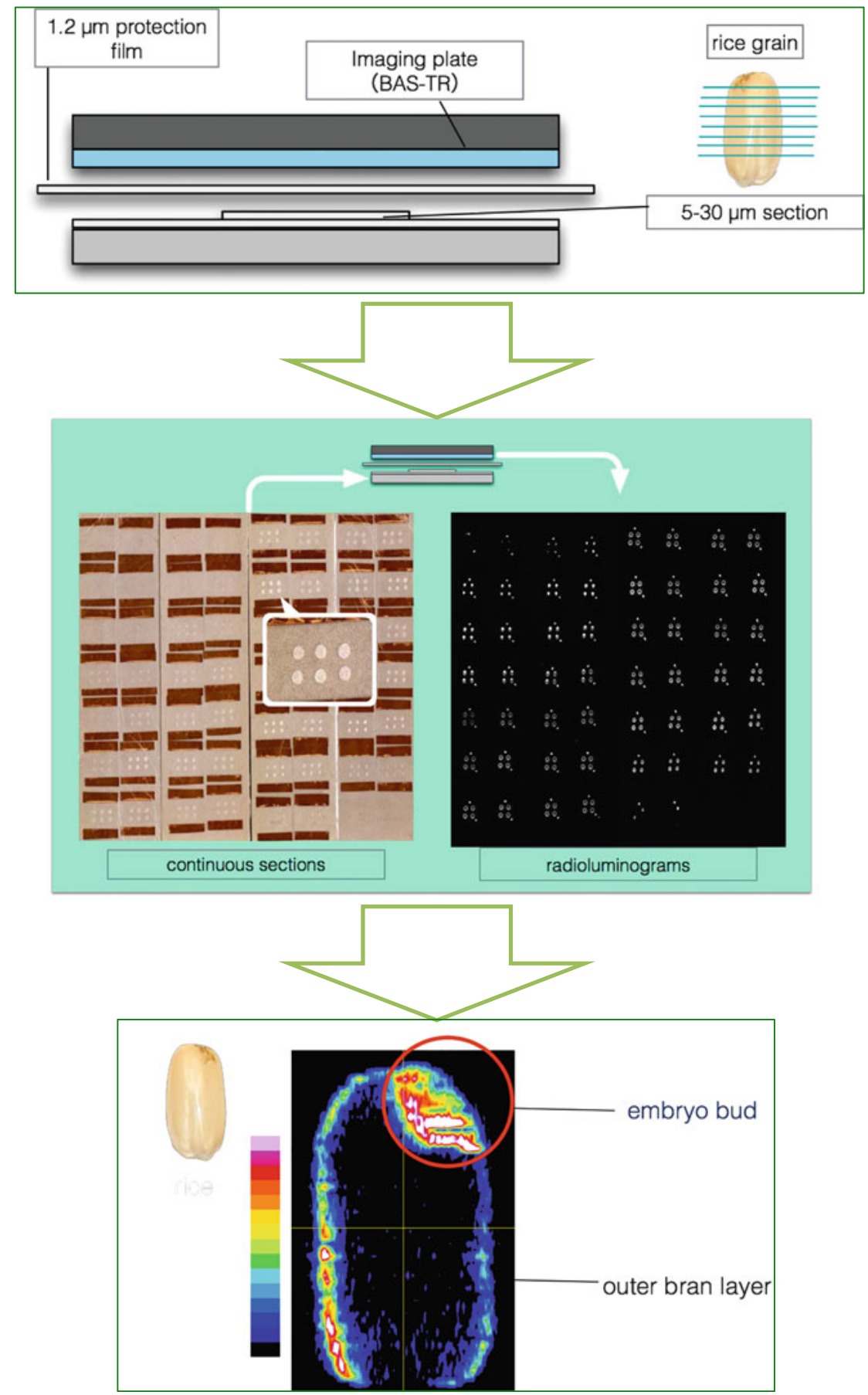

Fig. 19.4 The 3D construction from the sequential frozen sections in RLG. The sample shown here is a brown rice fed by ${ }^{137} \mathrm{Cs}$ 
to place the sample closer to the IP; hence, flat sections are important for high definition RLG imaging. However, the ionic form of nuclides, especially radiocesium, can move inside the plant during sectioning, such as during fixation and dehydration. For these reasons, we performed RLG on frozen samples to diminish radionuclide movement. The samples were immediately frozen with liquid nitrogen after slicing and stored at $-20^{\circ} \mathrm{C}$ until RLG imaging. We observed degree of contamination in peach tree bark samples from 2011, but most of the environmental samples were less contaminated and it was difficult to detect radiation in the thin sections. In general, frozen section imaging by RLG was applied to a laboratory experiment where we controlled the radionuclide levels in the samples.

The good correlation between radionuclide activity and photostimulated luminescence value for RLG with an IP allows the construction of three-dimensional (3D) images using sequential sections. For example, a rice plant was supplied with

${ }^{137} \mathrm{Cs}$ via the roots several days after flowering; the brown rice was sampled when the rice grain was mature and subsequently embedded in resin under freezing conditions. Also, preparation of sequential sections and exposure to an IP were performed under freezing conditions. After contact, the IP was scanned with the analyzer to obtain the radioluminograms and the ${ }^{137} \mathrm{Cs}$ distribution was reconstructed in 3D using Image J software (Fig. 19.4). The ${ }^{137} \mathrm{Cs}$ tended to accumulate in the embryo bud and outer bran layer.

\subsection{Microautoradiography}

Microautoradiography (MAR) is based on a technique that was used to take photographs several decades ago. The distribution of radionuclides can be visualized in greater detail by MAR than with RLG, although RLG has a greater quantitative ability and sensitivity than MAR. For these reasons, MAR is only performed to obtain finer images and for higher resolution of radionuclide distribution.

It is necessary to freeze the sample for the MAR procedure, similarly to RLG with frozen sections so, we have developed the MAR technique using/under frozen conditions (Hirose et al. 2014). Using MAR, we observed/could observe the ${ }^{137} \mathrm{Cs}$ distribution in a rice grain at a sub-millimeter resolution (Fig. 19.5). The distribution of ${ }^{137} \mathrm{Cs}$ was revealed at the tissue level and showed low ${ }^{137} \mathrm{Cs}$ activity in the plumule and radicle. These details were unclear in the images using RLG (Fig. 19.5).

Figure 19.6 is a summary of the imaging techniques applicable to frozen sections. A suitable technique must be chosen to achieve the scientific aim. 


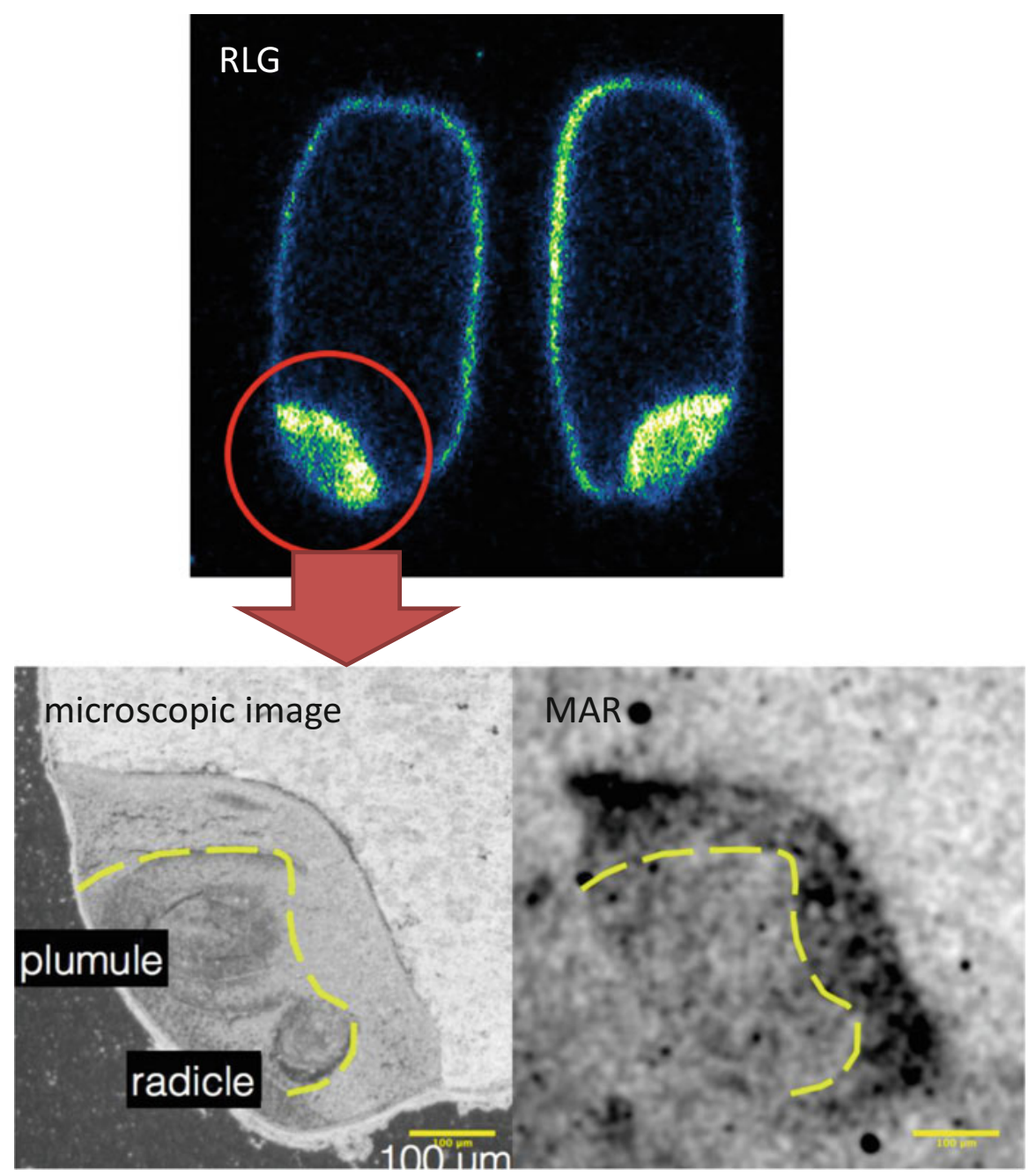

Fig. 19.5 The ${ }^{137} \mathrm{Cs}$ distribution in a rice grain visualized by RLG and MAR

\subsection{Real-Time Radioisotope Imaging System}

To understand the movement of solute in a plants, live imaging techniques are especially useful in such dynamic context. It is necessary for live imaging techniques to obtain data nondestructively. Radiation is a tool used to detect without destruction. Most of the live imaging systems using radiation or radionuclides are used in medicine, such as positron emission tomography (PET). There are several systems used to analyze plants using PET knowledge, such as the plant tomographic imaging system (PlanTIS) (Jahnke et al. 2009), or the positron emitting tracer imaging system (PETIS) (Fujimaki et al. 2010). In these systems, two annihilation 
Collecting samples with liquid nitrogen.

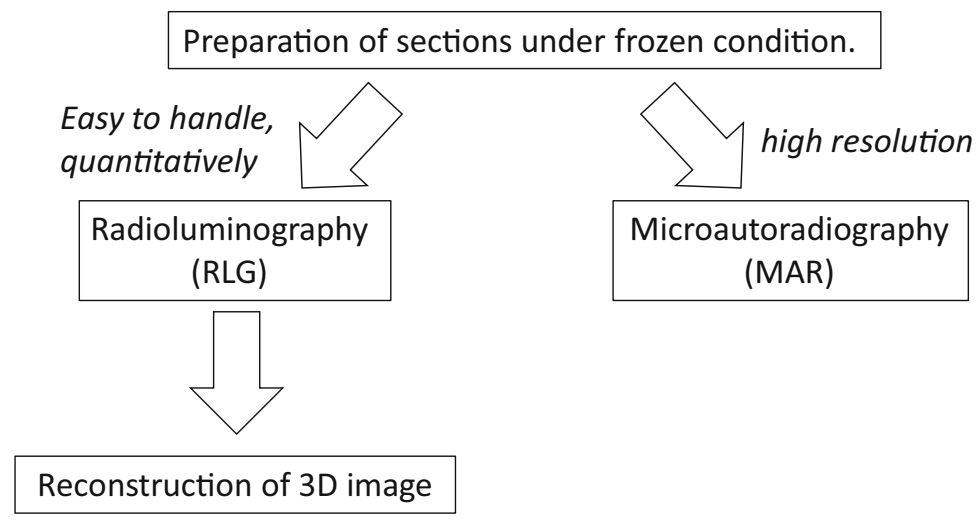

Fig. 19.6 Choice of the techniques to visualize the nuclides distribution of the sections

gamma rays, which are emitted from the positron emitting nuclide in a direction of $180^{\circ}$, are detected simultaneously so that the spatial distribution of the positron nuclide can be determined. Unfortunately, the half-lives of positron emitting nuclides tend to be too short to record the nuclides for several days, such as ${ }^{11} \mathrm{C}$ with a half-life of $20.39 \mathrm{~min}$. Moreover, there are a lot of elements that are important in plant nutrition or harmful in the human diet, but have no available positron emitting isotopes.

We have developed a live imaging system to analyze plants over a long period with conventional radionuclides, called real-time radioisotope imaging system (RRIS) (Nakanishi et al. 2009). The RRIS can be applied to many kinds of nuclides available on the market because beta-rays and soft X-rays can be detected and the dynamic range of detection is about 1000 times (Sugita et al. 2014); ${ }^{137} \mathrm{Cs}$, a betaray emitter, may be analyzed using this system.

\subsubsection{How to Detect Radionuclides in the System}

There are four steps to visualize the nuclide distribution in a plant sample (Fig. 19.7): (1) radiation is emitted from the radionuclides in a plant sample; (2) radiation is converted to photons (visible light), using a fiber optic plate with a scintillator (FOS); (3) visible light is converted to electrons, which are multiplied by a micro channel plate (MCP) with a GaAsP photoelectric surface; (4) electrons are detected using a charge-coupled device (CCD) camera. The image size is now $20 \mathrm{~cm} \times 10 \mathrm{~cm}$, and the resolution is around a few millimeters. To record the very 


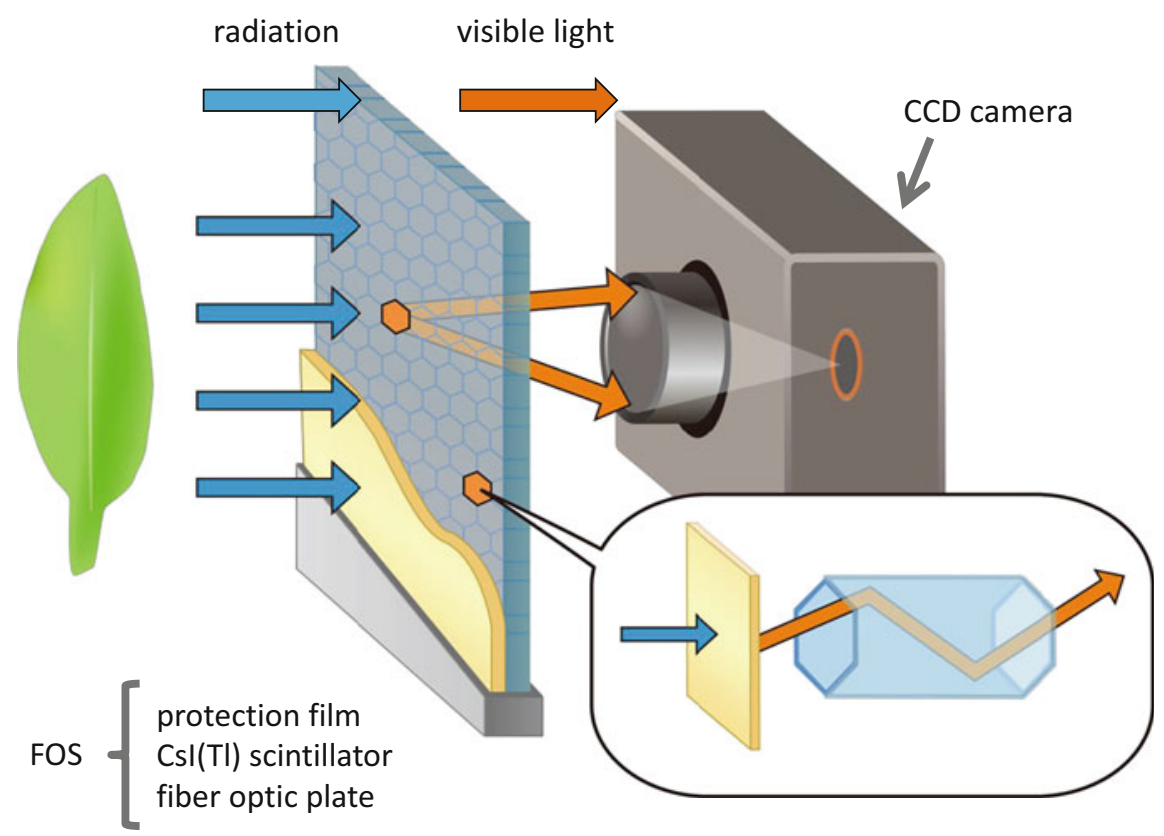

Fig. 19.7 How to make an image by real-time radioisotope imaging system. The radiation from the nuclides in a sample is converted to visible light by FOS containing scintillator. The CCD-camera catches the light sequentially

weak visible light, darkness is necessary between the scintillator and the camera. Thus, we used two types of plant chamber to illuminate the plant.

\subsubsection{Type I: Shielding from Light-Emitting Diodelight}

The plant was enclosed in an aluminum chamber containing light-emitting diode (LED) light to illuminate a plant leaf (Fig. 19.8 upper; (Yamawaki et al. 2010)). The thickness of aluminum between the plant and the FOS is $50-100 \mu \mathrm{m}$, which is enough to shield the visible light, but X-rays and relatively strong beta-rays can penetrate through the $100-\mu \mathrm{m}$ aluminum film. The chamber is set inside the dark box and the CCD camera records the photons released from the FOS. The Type I system can only be applied to nuclides that emit X-rays or relatively strong betarays.

\subsubsection{Type II: Intermittent Lighting System}

An intermittent lighting system is employed for the RRIS, whereby the LED light is on when the photon counting camera is off, and vice versa (Fig. 19.8 bottom). The 


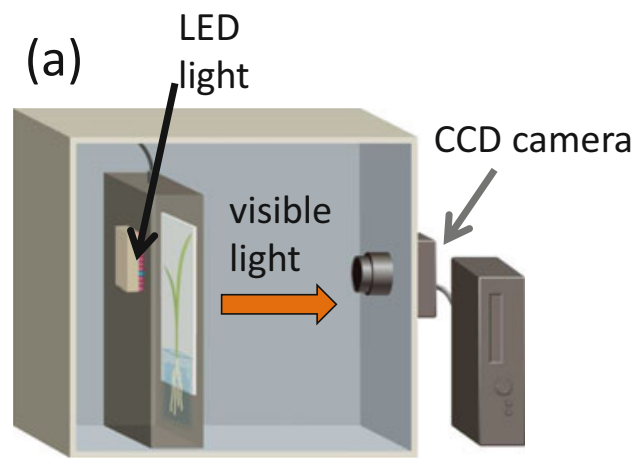

(b)
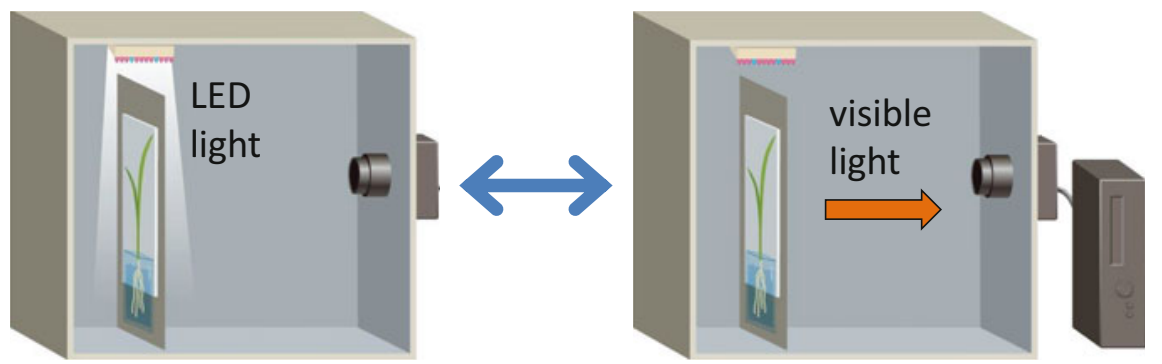

Fig. 19.8 Two types of chamber employed in the RRIS. (a) The chamber is covered with aluminum to prevent the LED light to leak to the CCD camera. (b) The chamber is open and the CCD light turns on only when the CCD camera is off

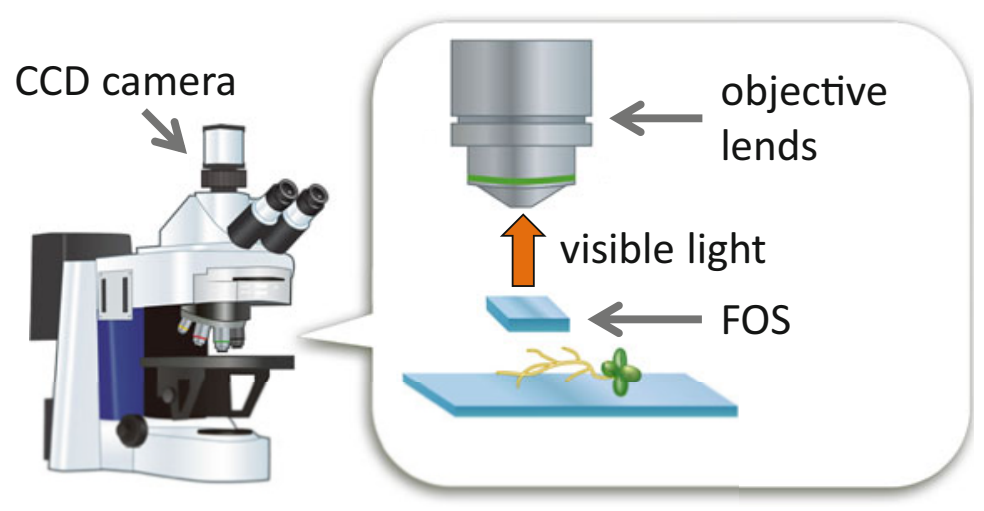

Fig. 19.9 Microscope installed with the RRIS. The radiation from the nuclides in a sample was converted to visible light by FOS and CCD camera captured the light passed through the objective lends 
type II system is used to analyze low energy beta emitters such as ${ }^{14} \mathrm{C},{ }^{35} \mathrm{~S}$, and ${ }^{45} \mathrm{Ca}$ as well as the higher energy beta emitters. However, darkness is still necessary during acquisition by the photon counting camera, which influences plant growth. Therefore, a shorter acquisition time would be better during the daytime.

In addition to the two systems, in order to observe in greater detail, we have developed a RRIS fluorescent microscopy system (Kobayashi et al. 2012) to provide sub-millimeter resolution and to acquire images of radionuclides, as well as fluorescence, chemiluminescence and differential interference contrast from a single sample (Fig. 19.9).

\subsubsection{Example: Real-Time Radioisotope Imaging System for Rice in a Paddy Soil}

To analyze the Cs movement around the roots (rhizosphere) in a rice plant, we performed a ${ }^{137} \mathrm{Cs}$ tracer experiment with paddy soil from Fukushima and rice plants (Fig. 19.10). We set the rice plant with or without soil in a chamber and collected sequential images every $10 \mathrm{~min}$. The rice plant without soil absorbed

${ }^{137} \mathrm{Cs}$ from the roots and transported it to the leaves within $4 \mathrm{~h}$ after ${ }^{137} \mathrm{Cs}$ addition, whereas a signal in the leaves of the rice plant with soil was detected $16 \mathrm{~h}$ after adding ${ }^{137} \mathrm{Cs}$, indicating that $\mathrm{Cs}$ fixation in the soil plays an important role to reduce Cs in the plant.

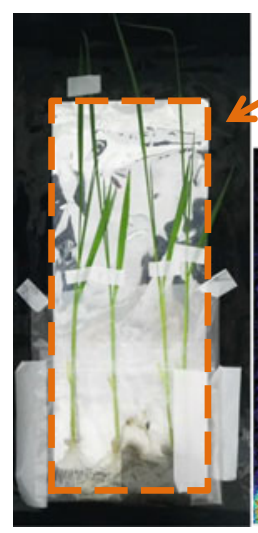

water soil photographing range

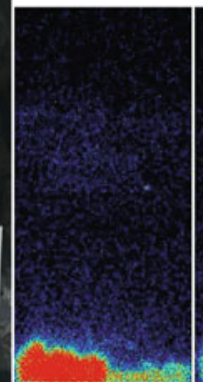

$\mathrm{Oh}$

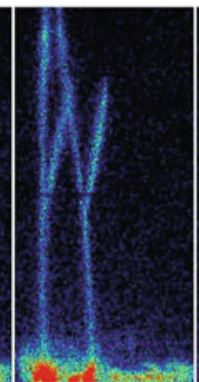

$4 \mathrm{~h}$

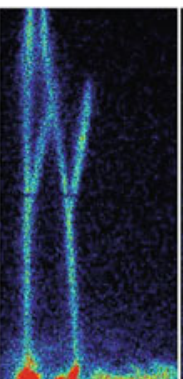

$8 \mathrm{~h}$

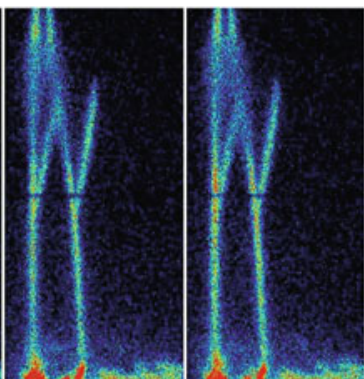

$12 \mathrm{~h}$
$16 \mathrm{~h}$

Fig. 19.10 The ${ }^{137} \mathrm{Cs}$ distribution in rice plants grown in a culture solution or paddy soil. The ${ }^{137} \mathrm{Cs}$ was added in a culture solution or paddy soil. The images were captured every $10 \mathrm{~min}$ 


\subsection{Potassium-42}

Cesium and $\mathrm{K}$ are both monovalent cations in a solution and their movement in animals and plants have been reported to be similar (Zhu and Smolders 2000; Hampton et al. 2005). A tracer experiment was needed to record the ions; however, there was no available isotope of potassium with a long half-life. Potassium-38 has a half-life of $7.6 \mathrm{~min}$, can be made by a cyclotron, and can be applied to plants (Tanoi et al. 2005); however, it is impossible to record it for several hours. Candidates for plant analysis are ${ }^{42} \mathrm{~K}$ (half-life is $12.4 \mathrm{~h}$ ) and ${ }^{43} \mathrm{~K}$ (half-life is $22.6 \mathrm{~h}$ ), which are generally made by a cyclotron (Clark et al. 1972) but not readily available. In order to use a more convenient potassium isotope, a ${ }^{42} \mathrm{Ar}-{ }^{42} \mathrm{~K}$ generator was used (Wegmann et al. 1981). Since the half-life of ${ }^{42} \mathrm{Ar}$ is about 33 years, the generator can provide ${ }^{42} \mathrm{~K}$ (a daughter nuclide of ${ }^{42} \mathrm{Ar}$ ) for several decades by milking from the ${ }^{42} \mathrm{Ar}-{ }^{42} \mathrm{~K}$ generator. The ${ }^{42} \mathrm{Ar}-{ }^{42} \mathrm{~K}$ generator was used commercially in Japan in the 1980s and now they are used for plant research. We introduce the use of ${ }^{42} \mathrm{~K}$ for researching potassium movement in a rice plant.

\subsubsection{Methods}

${ }^{42} \mathrm{~K}$ was obtained from the ${ }^{42} \mathrm{Ar}-{ }^{42} \mathrm{~K}$ generator using the method of Homareda (Homareda and Matsui 1986) with minor modifications. In this generator, ${ }^{42} \mathrm{Ar}$, produced by the ${ }^{40} \mathrm{Ar}(\mathrm{t}, \mathrm{p}){ }^{42} \mathrm{Ar}$ reaction in a cyclotron (Wegmann et al. 1981), decays to continuously produce ${ }^{42} \mathrm{~K}$. A steel cathode is inserted into the generator and (a tension of) approximately $60 \mathrm{~V}$ is applied to accumulate the positively charged ${ }^{42} \mathrm{~K}$ (Fig. 19.11). The cathode was then washed with a solution to extract the ${ }^{42} \mathrm{~K}^{+}$. The radioactivity of the extracted solution was measured using a liquid scintillation counter (LSC 6100; ALOKA).

\subsubsection{Examples}

The movement of ${ }^{42} \mathrm{~K}$ in a rice plant was visualized using RRIS as well as in an Arabidopsis (Aramaki et al. 2015). Two-weeks-old seedlings were placed in a RRIS chamber with $3 \mathrm{ml}$ of culture solution containing $6 \mathrm{kBq}$ of ${ }^{42} \mathrm{~K}$. The ${ }^{42} \mathrm{~K}$ signal from the sample was recorded every $15 \mathrm{~min}$ for $12 \mathrm{~h}$ and the signals were calculated by Image J software taking the half-life into account (Fig. 19.12). The signals coming from both the culture solution and the rice plants were observed by the system: this revealed that the rice plant absorbed most of the ${ }^{42} \mathrm{~K}$ in the culture solution in $3 \mathrm{~h}$. Using concurrent measurements, the movements of ${ }^{42} \mathrm{~K}$ and ${ }^{137} \mathrm{Cs}$ were compared. 

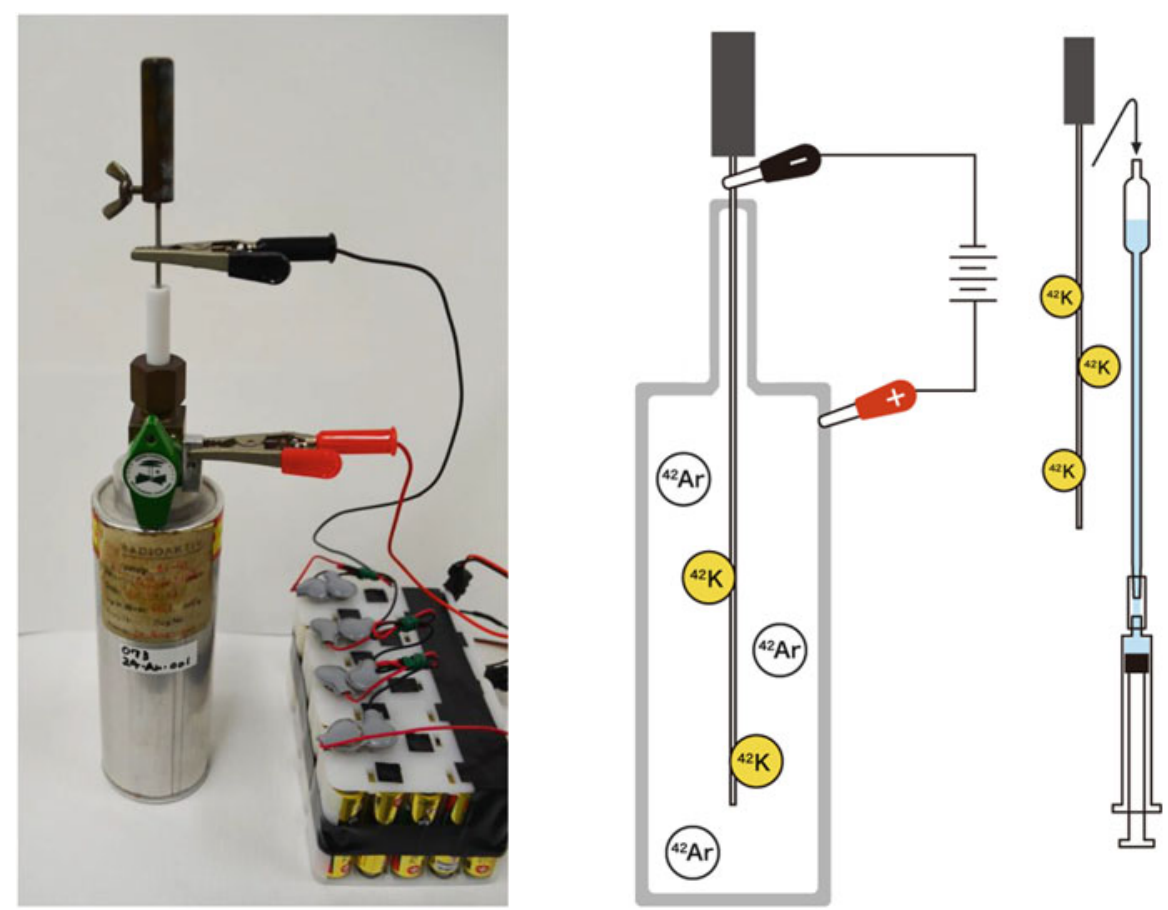

Fig. 19.11 The ${ }^{42} \mathrm{Ar}-{ }^{42} \mathrm{~K}$ generator. A charge of $60 \mathrm{~V}$ was applied to the cathode to attract ionized ${ }^{42} \mathrm{~K}$. A few days after, the extracting solution was filled into the pipette in which the cathode was placed to obtain the ${ }^{42} \mathrm{~K}$

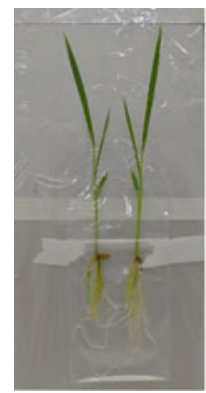

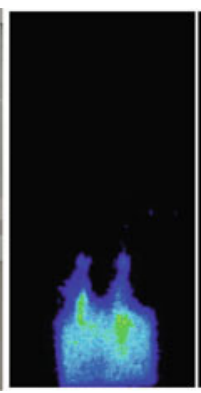

$\mathrm{Oh}$

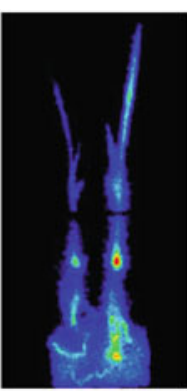

$3 \mathrm{~h}$

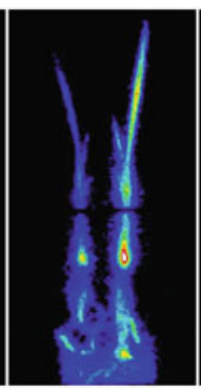

$6 \mathrm{~h}$

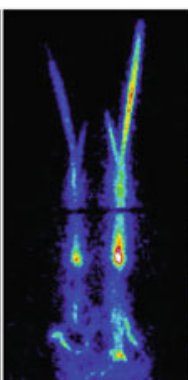

$9 \mathrm{~h}$

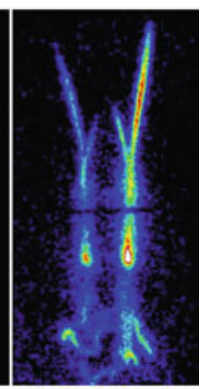

$12 \mathrm{~h}$

Fig. 19.12 ${ }^{42} \mathrm{~K}$ distribution in a rice plant observed by RRIS. The images were captured every 15 min and the shown images were calculated considering the half life of ${ }^{42} \mathrm{~K}$ 


\subsection{Summary}

We introduced some new techniques for visualizing radionuclides including radiocesium. There are several choices of imaging techniques. To observe the radiocesium distribution in a thin sample, RLG with an IP would be the most convenient technique. When it is necessary to observe the radiocesium distribution in detail, frozen section imaging with RLG or MAR are useful for the distribution can be observed at a resolution of tens to hundreds of micrometers. As a live imaging system, RRIS can contribute to understanding the movement of radiocesium in plants. With these imaging techniques, as well as with nuclides such as ${ }^{137} \mathrm{Cs},{ }^{42} \mathrm{~K}$, and ${ }^{22} \mathrm{Na}$, we can access important information to solve the problem of radiocesium contamination in crops, plants, and the environment.

Acknowledgement The authors thank Xerri, Sophie-Asako for critical reading of the manuscript

Open Access This chapter is distributed under the terms of the Creative Commons Attribution Noncommercial License, which permits any noncommercial use, distribution, and reproduction in any medium, provided the original author(s) and source are credited.

\section{References}

Aramaki T, Sugita R, Hirose A et al (2015) Application of ${ }^{42} \mathrm{~K}$ to Arabidopsis tissues using RealTime Radioisotope Imaging System (RRIS). Radioisotopes 64:169-176. doi:10.3769/radioiso topes. 64.169

Clark JC, Thakur ML, Watson IA (1972) The production of potassium-43 for medical use. Int J Appl Radiat Isot 23:329-330. doi:10.1016/0020-708X(72)90011-7

Fujimaki S, Suzui N, Ishioka NS et al (2010) Tracing cadmium from culture to spikelet: noninvasive imaging and quantitative characterization of absorption, transport, and accumulation of cadmium in an intact rice plant. Plant Physiol 152:1796-1806. doi:10.1104/pp. 109. 151035

Furuta E (2013) Semi-quantitative analysis of leaf surface contamination by radioactivity from the Fukushima Daiichi nuclear power plant accident using HPGe and imaging plate. J Radioanal Nucl Chem 297:337-342. doi:10.1007/s10967-012-2343-4

Hampton C, Broadley M, White P (2005) Short review: the mechanisms of radiocaesium uptake by Arabidopsis roots. Nukleonika 50(suppl1):3-8

Hirose A, Kobayashi NI, Tanoi K, Nakanishi TM (2014) A microautoradiographic method for fresh-frozen sections to reveal the distribution of radionuclides at the cellular level in plants. Plant Cell Physiol 55:1194-1202. doi:10.1093/pcp/pcu056

Homareda H, Matsui H (1986) Biochemical utilization of ${ }^{42} \mathrm{Ar}^{4}{ }^{42} \mathrm{~K}$ generator. Radioisotopes 35:543-546. doi:10.3769/radioisotopes.35.10_543

Isobe T, Mori Y, Takada K et al (2013) Evaluation of vegetables in Tsukuba for contamination with radioactive materials from the accident at Fukushima Daiichi nuclear power plant. Health Phys 105:311-317. doi:10.1097/HP.0b013e3182895759

Itoh S, Eguchi T, Kato N, Takahashi S (2014) Radioactive particles in soil, plant, and dust samples after the Fukushima nuclear accident. Soil Sci Plant Nutr 60:540-550. doi:10.1080/00380768. 2014.907735 
Jahnke S, Menzel MI, van Dusschoten D et al (2009) Combined MRI-PET dissects dynamic changes in plant structures and functions. Plant J 59:634-644. doi:10.1111/j.1365-313X.2009. 03888.x

Kanno S, Rai H, Ohya T et al (2007) Real-time imaging of radioisotope labeled compounds in a living plant. J Radioanal Nucl Chem 272:565-570. doi:10.1007/s10967-007-0625-Z

Kobayashi NI, Tanoi K, Kanno S, Nakanishi TM (2012) Analysis of the iron movement in the root tip part using real-time imaging system. Radioisotopes 61:121-128. doi:10.3769/radioisotopes. 61.121

Koizumi A, Niisoe T, Harada KH et al (2013) ${ }^{137} \mathrm{Cs}$ trapped by biomass within $20 \mathrm{~km}$ of the Fukushima Daiichi nuclear power plant. Environ Sci Technol 47:9612-9618. doi:10.1021/ es401422g

Mimura T, Mimura M, Kobayashi D et al (2014) Radioactive pollution and accumulation of radionuclides in wild plants in Fukushima. J Plant Res 127:5-10. doi:10.1007/s10265-0130599-6

Mori S, Hirato A, Tanoi K et al (2012) Radioactive cesium flow in Rhus vernicifera. Soil Sci Plant Nutr 58:611-617. doi:10.1080/00380768.2012.727188

Mukai H, Hatta T, Kitazawa H et al (2014) Speciation of radioactive soil particles in the Fukushima contaminated area by IP autoradiography and microanalyses. Environ Sci Technol 48:13053-13059. doi:10.1021/es502849e

Nakajima H, Fujiwara M, Tanihata I et al (2014) Imaging plant leaves to determine changes in radioactive contamination status in Fukushima, Japan. Health Phys 106:565-570

Nakanishi T, Yamawaki M, Kannno S et al (2009) Real-time imaging of ion uptake from root to above-ground part of the plant using conventional beta-ray emitters. J Radioanal Nucl Chem 282:265-269. doi:10.1007/s10967-009-0343-9

Nakanishi TM, Kobayashi NI, Tanoi K (2012) Radioactive cesium deposition on rice, wheat, peach tree and soil after nuclear accident in Fukushima. J Radioanal Nucl Chem. doi:10.1007/ s10967-012-2154-7

Nakanishi H, Tanaka H, Takeda K et al (2014) Radioactive cesium distribution in bamboo [Phyllostachys reticulata(Rupr) K. Koch] shoots after the TEPCO Fukushima Daiichi nuclear power plant disaster. Soil Sci Plant Nutr 60:801-808. doi:10.1080/00380768.2014.939936

Niimura N, Kikuchi K, Tuyen ND et al (2014) Physical properties, structure, and shape of radioactive Cs from the Fukushima Daiichi Nuclear Power Plant accident derived from soil, bamboo and shiitake mushroom measurements. J Environ Radioact. doi:10.1016/j.jenvrad. 2013.12.020

Sakamoto F, Ohnuki T, Kozai N et al (2013) Determination of local-area distribution and relocation of radioactive cesium in trees from Fukushima Daiichi nuclear power plant by autoradiography analysis. Trans At Energy Soc Jpn 12:257-266

Shiba K, Kitamura Y, Kozaka T et al (2013) Decontamination of radioactivity from contaminated vegetables derived from the Fukushima nuclear accident. Radiat Meas 55:26-29. doi:10.1016/ j.radmeas.2013.01.010

Sugita R, Kobayashi NI, Hirose A et al (2014) Evaluation of in vivo detection properties of ${ }^{22} \mathrm{Na}$, ${ }^{65} \mathrm{Zn},{ }^{86} \mathrm{Rb},{ }^{109} \mathrm{Cd}$ and ${ }^{137} \mathrm{Cs}$ in plant tissues using real-time radioisotope imaging system. Phys Med Biol 59:837-851. doi:10.1088/0031-9155/59/4/837

Suzuki T, Mori C, Yanagida K et al (1997) Characteristics and correction of the fading of imaging plate. J Nucl Sci Technol 34:461-465. doi:10.1080/18811248.1997.9733692

Takata D, Yasunaga E, Tanoi K et al (2012) Radioactivity distribution of the fruit trees ascribable to radioactive fall out (III): a study on peach and grape cultivated in south Fukushima. Radioisotopes 61:601-606

Tanaka K, Iwatani H, Sakaguchi A et al (2013) Local distribution of radioactivity in tree leaves contaminated by fallout of the radionuclides emitted from the Fukushima Daiichi Nuclear Power Plant. J Radioanal Nucl Chem 295:2007-2014. doi:10.1007/s10967-012-2192-1

Tanoi K (2013) Behavior of radiocesium adsorbed by the leaves and stems of wheat plant during the first year after the Fukushima Daiichi nuclear power plant accident. In: Nakanishi TM, 
Tanoi K (eds) Agricultural implications of the Fukushima nuclear accident. Springer Japan, Tokyo, pp 11-18

Tanoi K, Hojo J, Suzuki K et al (2005) Analysis of potassium uptake by rice roots treated with aluminum using a positron emitting nuclide, K-38. Soil Sci Plant Nutr 51:715-717

Tanoi K, Hashimoto K, Sakurai K et al (2011) An imaging of radioactivity and determination of an imaging of radioactivity and determination of Cs-134 and Cs-137 in wheat tissue grown in Fukushima. Radioisotopes 60:317-322. doi:10.3769/radioisotopes.60.299

Wegmann H, Huenges E, Muthig H, Morinaga H (1981) Acceleration of tritons with a compact cyclotron. Nucl Instrum Methods 179:217-222. doi:10.1016/0029-554X(81)90042-2

Yamaguchi T, Sawano K, Furuhama K et al (2013) An autoradiogram of skeletal muscle from a pig raised on a farm within $20 \mathrm{~km}$ of the Fukushima Daiichi nuclear power plant. J Vet Med Sci 75:93-94

Yamawaki M, Hirose A, Kanno S et al (2010) Evaluation of ${ }^{109} \mathrm{Cd}$ detection performance of a realtime RI imaging system for plant research. Radioisotopes 59:155-162

Zeissler CJ, Forsley LPG, Lindstrom RM et al (2013) Radio-microanalytical particle measurements method and application to Fukushima aerosols collected in Japan. J Radioanal Nucl Chem 296:1079-1084. doi:10.1007/s10967-012-2135-x

Zhu YG, Smolders E (2000) Plant uptake of radiocaesium: a review of mechanisms, regulation and application. J Exp Bot 51:1635-1645 